\title{
Combination Drug Therapy
}

National Cancer Institute

\section{Source}

National Cancer Institute. Combination Drug Therapy. NCI Thesaurus. Code C16144.

Drug therapy with two or more drugs given separately or together for a combined effect. 